\title{
Unity or diversity of executive functioning in children and adolescents with post-traumatic stress symptoms? A systematic review and meta- analysis
}

\section{Otelie Nyvold, Egil Nygaard, Else-Marie Augusti \& Christian K. Tamnes}

To cite this article: Otelie Nyvold, Egil Nygaard, Else-Marie Augusti \& Christian K. Tamnes (2021): Unity or diversity of executive functioning in children and adolescents with post-traumatic stress symptoms? A systematic review and meta-analysis, Child Neuropsychology, DOI: 10.1080/09297049.2021.1979950

To link to this article: https://doi.org/10.1080/09297049.2021.1979950
(c) 2021 The Author(s). Published by Informa UK Limited, trading as Taylor \& Francis Group.

曲 Published online: 23 Sep 2021.

Џll Article views: 511

\section{+ View supplementary material} .
Submit your article to this journal $\square$ 


\title{
Unity or diversity of executive functioning in children and adolescents with post-traumatic stress symptoms? A systematic review and meta-analysis
}

\author{
Otelie Nyvold ${ }^{\mathrm{a}}$, Egil Nygaard $\mathbb{D}^{\mathrm{b}}{ }^{\mathrm{b}}$, Else-Marie Augusti $\mathbb{D D}^{\mathrm{c}}$ and Christian K. Tamnes $\mathbb{D}^{\mathrm{d}, \mathrm{e}, \mathrm{f}}$
}

${ }^{a}$ Nic Waals Institute, Lovisenberg Hospital, Oslo, Norway; bepartment of Psychology, University of Oslo, Oslo, Norway; 'Norwegian Centre for Violence and Traumatic Stress Studies, Oslo, Norway; ${ }^{\text {dPROMENTA }}$

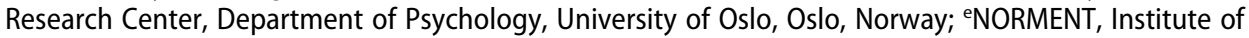

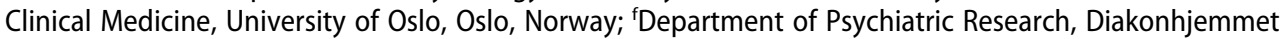
Hospital, Oslo, Norway

\begin{abstract}
For some children, psychological reactions to a traumatic event develop into severe or persistent post-traumatic stress symptoms (PTSS) or the clinical condition of post-traumatic stress disorder (PTSD). Cognitive problems in children with PTSS have been reported, but it is not clear which specific functions are affected. Executive functions is a domain of particular interest, given its importance for academic performance and social and emotional functioning. A systematic literature search was performed, and 12 studies with 55 comparisons of executive functions in children with PTSS and healthy controls were eligible for meta-analysis. A subset of the studies also included a comparison group of children with traumatic experienced but without PTSS. Overall, across all tasks and measures, children with PTSS showed lower executive functioning than healthy controls (SMD $=-0.57)$. The effect sizes between the subdomains complex tasks, verbal fluency, inhibition, shifting and working memory were not significantly different from each other, but was largest for verbal fluency (SMD $=-1.45$ ). Analyses comparing children with traumatic experiences with and without PTSS similarly showed overall lower executive functioning in the PTSS group (SMD $=-0.34$ ) and no significant differences in effect sizes between subdomains. The results have implications for assessment and clinical work with youth exposed to traumatic events. We should be aware of the poor executive functioning that may be an issue for some children with a history of trauma and subsequent development of PTSS, and the impact this could have on everyday functioning.
\end{abstract}

\section{ARTICLE HISTORY}

Received 5 January 2021

Accepted 8 September 2021

\section{KEYWORDS}

Children; cognition; executive functions; posttraumatic stress disorder; trauma

Most individuals will experience one or more potentially traumatic experience during childhood (Gilbert et al., 2009; McLaughlin et al., 2013). These types of experiences include the death of a loved one, witnessing or suffering serious accidents or injuries, natural disasters, and child maltreatment such as physical, emotional or sexual abuse. 
Traumatic experiences can have a profound impact on children's development, and is on a group level associated with physical and mental health problems in both short and long-term perspectives (Appleyard et al., 2005; Felitti, 2002). One such consequence is an increased risk of developing post-traumatic stress symptoms (PTSS) such as intrusive reexperiencing, avoidance, negative effects and hyper arousal. It is estimated that about $16 \%$ of all traumatized children will develop posttraumatic stress disorder (PTSD) (Alisic et al., 2014) and an unknown, presumably larger, proportion may develop PTSS without completely fulfilling the criteria for a PTSD diagnosis. Traumatic experiences and PTSS have both been associated with reduced cognitive functioning relative to performance in healthy control (Malarbi et al., 2017; Scott et al., 2015), with potential consequences for everyday functioning (Biederman et al., 2004; Danzi \& La Greca, 2017). One of the cognitive domains that appears to be most affected is executive functions (Kavanaugh et al., 2017; Op den Kelder et al., 2018).

Executive functions are high-level cognitive processes that control lower-level processes and enable goal-directed behavior (Friedman \& Miyake, 2017). An influential model of executive functions is the unity and diversity model proposed by Miyake, Friedman and colleagues (Friedman \& Miyake, 2017; Miyake et al., 2000). Based on confirmatory factor analysis of behavioral data from several relatively simple behavioral tasks, they identified a taxonomy distinguishing between specific executive functions, including inhibition, shifting and working memory. Inhibition is the ability to suppress distracting information or to stop responses. Shifting allows individuals to flexibly switch their attention between different tasks, operations, or mental sets. Working memory is the active ability to code, maintain and replace accurate mental representations of information changing over time. Other specific executive functions have also been described, including verbal fluency, which involved spontaneous information retrieval from memory and response generation, although results indicate that this function is also closely related to language functions (Whiteside et al., 2016). Notably, specific executive functions correlate, but are also separable, in other words they show both unity and diversity (Friedman \& Miyake, 2017). Less pure behavioral tasks can be considered complex executive function tasks in that rely on broader sets of cognitive functions (Miyake et al., 2000). Executive functions are also closely tied to emotion regulation, as both can be considered "top-down" elements of self-regulation (Palacios-Barrios \& Hanson, 2019).

Executive functions have complicated and particularly extended developmental courses, possibly making them vulnerable to traumatic experiences and psychopathology during childhood and adolescence. Alternatively, atypical development of executive functions may make some children particularly vulnerable. The development of executive functions during childhood involves qualitative changes in the structure or organization of functions, with increasing differentiation between different specific functions with increasing age (Akshoomoff et al., 2018; Hartung et al., 2020; Lee et al., 2013; Zhang et al., 2021). This both overlaps with and is followed by gradual quantitative improvements continuing throughout childhood and adolescence (Huizinga et al., 2006; Lehto et al., 2003; Tamnes et al., 2010). Performance on shifting tasks improves at least into midadolescence, while inhibition and working memory likely continue to improve into young adulthood (Huizinga et al., 2006; Prencipe et al., 2011; Theodoraki et al., 2020). This protracted development of executive functions parallels the lengthy structural development of prefrontal cortical regions (Baum et al., 2020; Fiske \& Holmboe, 2019; 
Norbom et al., 2021; Tamnes et al., 2013) and white matter tracts that connect prefrontal regions with other parts of the brain (Geeraert et al., 2019; Goddings et al., 2021; Lebel \& Beaulieu, 2011). In addition to being a core aspect of the development of complex cognitive functions, executive functions are predictive of academic performance at school beyond general cognitive abilities (Donati et al., 2019), and are also important for social behavior both in school and in other settings (McClelland \& Cameron, 2012). The development of executive functions is also linked to the ability to successfully regulate emotions (Schweizer, Gotlib et al., 2020; Schweizer, Parker et al., 2020), which is an important vulnerability and resiliency factor for the development of trauma symptoms (Christ et al., 2019; Dvir et al., 2014; Heleniak et al., 2016). Impairments in executive functions in youth with PTSS may therefore have a range of tangible consequences.

The few studies to date that have scrutinized the question of whether cognitive functions, and specifically executive functions, are differentially impaired depending on the presence of PTSS or not in youth after trauma exposure have shown mixed results (Barrera et al., 2013; De Bellis et al., 2009; Saigh et al., 2006; Scrimin et al., 2006). On the one hand, studies find impaired learning, memory and cognitive flexibility in children with PTSD as compared to trauma-exposed children without symptoms of PTSD (Samuelson et al., 2010; Schoeman et al., 2009; Yasik et al., 2007). On the other hand, no differences have been reported between these groups of trauma-exposed children on general intellectual abilities, attention, working memory, inhibition and memory (Samuelson et al., 2010; Yang et al., 2014). When comparing trauma-exposed children with and without PTSD to healthy controls, one study documented poorer general and verbal intellectual abilities in the PTSD group exclusively (Saigh et al., 2006). When investigating this question meta-analytically, Malarbi et al. (2017) found a slight impairment in executive functioning in the PTSD/PTSS groups as compared to groups of trauma-exposed children without PTSD and healthy controls.

The aim of this systematic review and meta-analysis was to explore the nature of executive functioning in children and adolescents with PTSS. Specifically, we aimed to address the following research questions: 1. Do children and adolescents with PTSS show global or specific deficits in executive functions compared to healthy controls?, and 2. Do youth with PTSS show greater impairments in executive functions compared to youth exposed to traumatic events without PTSS? To address these questions, we performed meta-analyses on group-level differences between children with PTSS and health controls and between children with PTSS and children with traumatic experiences but without PTSS in performance on tasks considered to measure executive functioning. We chose to focus on executive functioning given their extended developmental course and their importance for academic performance and social and emotional functioning. We analyzed executive functions both on a general level across all available tasks and measures and for specific subdomains, including verbal fluency, inhibition, shifting, and working memory, as well on performance on complex executive function tasks. Dividing the tasks and measures into different executive function subdomains may aid in specifying the executive function difficulties associated with PTSS. Based on previous work (Kavanaugh et al., 2017; Malarbi et al., 2017; Op den Kelder et al., 2018; Scott et al., 2015), we hypothesized that children with PTSD would show overall poorer executive function performance than both healthy control and children with traumatic experiences without PTSD, while we considered our analyses of executive function subdomains explorative. 
Previous reviews (Kavanaugh et al., 2017; Pechtel \& Pizzagalli, 2011; Perkins \& GrahamBermann, 2012) and meta-analyses (Johnson et al., 2021; Malarbi et al., 2017; Op den Kelder et al., 2018) have focussed on associations between early-life stress or trauma exposure and functioning in different cognitive domains in children and adolescents. Instead, we chose to focus on cognitive functioning in children and adolescents with PTSS, rather than on groups with reported experienced traumatic events. This is an important distinction as only a minority of traumatized children will develop persisting and severe symptoms after trauma (McLaughlin et al., 2013). One exception is a metaanalysis of cognitive functioning in adults with PTSD (Scott et al., 2015), but this study excluded individuals below 18 years. A systematic review and meta-analysis of executive functioning in youth with PTSS is thus needed. Knowledge about executive functioning in children and adolescents with PTSS is important as these functions may be effective targets for intervention after trauma (Schweizer et al., 2017). Identifying whether children and adolescents struggle with specific executive functions or with executive functions more globally may guide future research and clinical work on how to intervene most effectively.

\section{Methods}

\section{Search strategy and study selection}

The present systematic review and meta-analysis is based on the Preferred reporting items for systematic reviews and meta-analyses (PRISMA) 27-item checklist and flow diagram (Moher et al., 2009). The literature search was performed February, 2021 in Scopus and Ovid (covering PubMed, Embase and Psychinfo) with the search phrase ("ptsd" OR "ptss" OR "post-traumatic stress" OR "posttraumatic stress") AND ("executive*” OR "cognitive control") AND ("child»" OR "adolescen*” OR "youth" OR "pediatr").To limit the number of non-relevant hits, specific executive function subdomain terms were not included in the search. All abstracts were read for screening, and the eligibility criteria were: 1) original studies in English 2) using behavioral tasks to measure executive functions 3 ) in children ( $<18$ years) 4$)$ with PTSD or PTSS as determined either by a psychiatrist/psychologist or by self- or parent-report and 5) with a control group without PTSD or PTSS. Studies using questionnaires to measure executive functions were excluded, as were studies focused on other patient groups or the effects of interventions. Relevant references were cross-checked for further relevant studies. All eligible studies were read in full by two of the authors (ON, CKT) and inclusion was made by consensus. We contacted authors of all articles that met the inclusion criteria, but which did not report group means and standard deviations for the executive function measures. The results of the screening and selection procedure is detailed below.

The following information was extracted from the included studies: authors, year of publication, journal, study location, mean age, trauma type, executive function tests used, number of participants per group, and means and standard deviations of executive function task scores per group. All relevant task scores were included, although it was not consistently reported whether these scores were age-normed scores or raw scores. The different executive function test were then, based on discussion and consensus among the authors, categorized into the following five subdomains: complex, verbal fluency, inhibition, shifting, and working memory. 


\section{Statistical analyses}

The statistical analyses were performed in R4.0.2 and RStudio 1.3.959 (https://www. r-project.org/). The package meta,version 4.15-1 (Balduzzi et al., 2019) was used to perform meta-analyses with executive function subdomains defined as subgroups, to create forest plots and funnel plots, and for regression analyses. We used the package metafor,version 2.4-0 (Viechtbauer, 2010) for sensitivity analyses to investigate whether clustering/multilevel effects of including multiple results from the same study influenced the results. As we expected the studies to be heterogeneous, we used random effects models. All available executive function performance scores from the studies were included separately. Each study could thus potentially contribute with multiple outcomes measures. In addition to examining group differences in executive functioning across all included tasks and measures, subgrouplevel analyses allowed us to examine and compare group differences within and between each of the five executive function subdomains; complex, verbal fluency, inhibition, shifting, and working memory. We performed two separate analyses; one where we compared children with PTSS to healthy controls, and one where we compared children with PTSS to children exposed to traumatic events but without PTSS. Linear regression analyses were performed to investigate whether mean age of participants or publishing year influenced the results.

The reported effect sizes are bias-corrected standardized mean differences (Hedges' g) (SMD) between the two groups. Negative effect sizes will here indicate that the group of children with PTSS performed worse than the control group. To ease interpretation, error and reaction time-based difference scores were calculated in the opposite direction, again so that negative effects indicate lower performance in the group of children with PTSS. Chi-square test (Q), tau, and $\mathrm{I}^{2}$ were used to assess heterogeneity, both within each executive function subdomain and across all measures. Significance level $5 \%$ was chosen for all analyses.

\section{Bias evaluation}

Each study was subjectively evaluated to have low, unclear or high risk with respect to six possible biases (selection, performance, detection, attrition, reporting and other bias), based on Higgins et al. (2011). The risk of bias was individually assessed by two of the authors (ON and CKT). In cases of discrepancies between the two authors, consensus was researched after discussion. Studies were included irrespective of their assessed quality. Funnel plots were created to assess publication bias and interpreted according to recommendations by Sterne et al. (2011).

\section{Results}

\section{Study selection}

The database search identified 325 studies after removing duplicates and after adding 2 relevant studies identified though other sources. After screening, 293 of these were excluded, while 33 articles were assessed in detail for eligibility. From these 33 studies, 12 studies were included in the meta-analyses, 6 of which had two control groups; healthy 


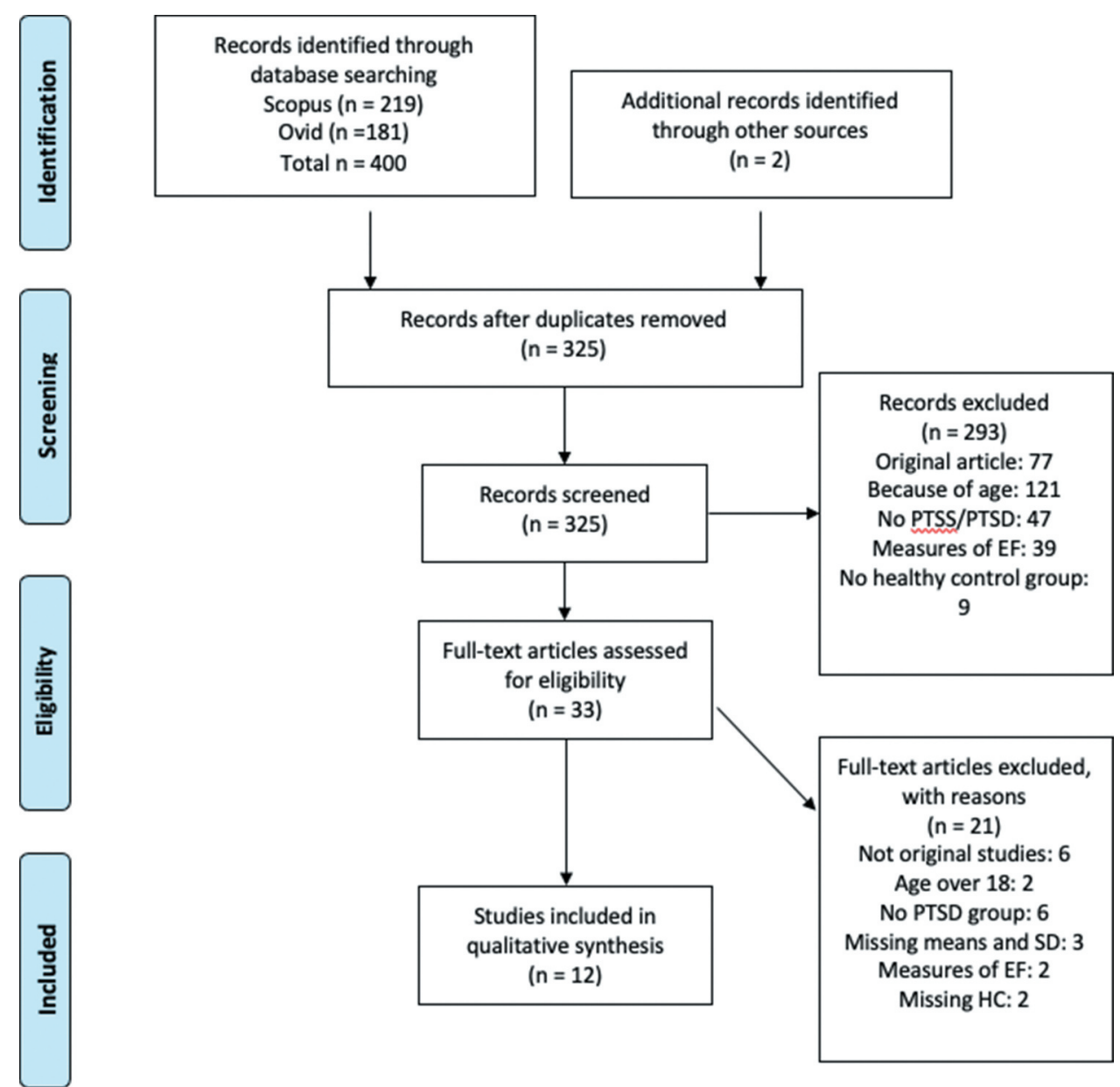

Figure 1. Flow diagram for the screening and selection procedure for studies in this meta-analysis.

controls and children exposed to traumatic events without PTSS. The results of the study screening and selection process is further described in Figure 1. Details of the studies included in the meta-analysis are presented in Table 1.

In all the 12 studies included in the meta-analysis, except three (Kavanaugh et al., 2015; Mueller et al., 2015; Park et al., 2014), the presence of PTSS or PTSD was determined with clinical interviews or with a clinician-administered scale. The definition and assessment of executive functions varied in the included studies. Some tasks were used in many of the included studies, whereas other tasks were less frequently used. The most frequently measured subdomains were complex executive functions and inhibition. The most frequently used task within these two subdomains was the Wisconsin Card Sorting Task and the Stroop ColorWord Task, respectively. 
Table 1. Studies included in the meta-analyses.

\begin{tabular}{|c|c|c|c|c|c|c|}
\hline Study & Journal & $\begin{array}{l}\text { Study } \\
\text { location }\end{array}$ & $\begin{array}{l}\text { Number of } \\
\text { participants }\end{array}$ & $\begin{array}{c}\text { Age } \\
\text { (mean) }\end{array}$ & $\begin{array}{l}\text { Trauma } \\
\text { type }\end{array}$ & $\begin{array}{l}\text { Executive function } \\
\text { subdomains and tasks }\end{array}$ \\
\hline $\begin{array}{l}\text { Beers and De } \\
\text { Bellis (2002) }\end{array}$ & $\begin{array}{l}\text { American Journal of } \\
\text { Psychiatry }\end{array}$ & USA & $\begin{array}{l}\text { PTSS: } 14 \\
\text { HC: } 15\end{array}$ & 11.8 & Familial & $\begin{array}{l}\text { Complex: WCST } \\
\text { Verbal fluency: } \\
\text { COWAT } \\
\text { Inhibition: Stroop } \\
\text { Color-Word } \\
\text { Shifting: TMT }\end{array}$ \\
\hline $\begin{array}{l}\text { Biedermann } \\
\text { et al. (2018) }\end{array}$ & Child Abuse \& Neglect & South Africa & $\begin{array}{l}\text { PTSS + CSA: } 18 \\
\text { PTSS: } 34 \\
\text { CSA - PTSS: } 16 \\
\text { HC: } 37\end{array}$ & 15.3 & Sexual & $\begin{array}{l}\text { Complex: WCST } \\
\text { Verbal fluency: } \\
\text { COWAT } \\
\text { Shifting: TMT } \\
\text { WM: Digit span } \\
\text { backwards }\end{array}$ \\
\hline $\begin{array}{l}\text { Carrion et al. } \\
\qquad(2008)\end{array}$ & $\begin{array}{l}\text { Depression and } \\
\text { Anxiety }\end{array}$ & USA & $\begin{array}{l}\text { PTSS: } 16 \\
\text { HC: } 14\end{array}$ & 13.5 & $\begin{array}{l}\text { Familiar } \\
\text { and } \\
\text { sexual }\end{array}$ & Inhibition: Go/Go-No \\
\hline $\begin{array}{l}\text { De Bellis et al. } \\
\text { (2009) }\end{array}$ & $\begin{array}{l}\text { Journal of the } \\
\text { International } \\
\text { Neuropsychological } \\
\text { Society }\end{array}$ & USA & $\begin{array}{l}\text { PTSS: } 22 \\
\text { TE: } 39 \\
\text { HC: } 45\end{array}$ & 8.0 & Familial & $\begin{array}{l}\text { Complex: NEPSY } \\
\text { tower } \\
\text { Inhibition: CPT }\end{array}$ \\
\hline $\begin{array}{l}\text { De Bellis et al. } \\
\text { (2013) }\end{array}$ & Child Maltreatment & USA & $\begin{array}{l}\text { PTSS: } 60 \\
\text { TE: } 38 \\
\text { HC: } 104\end{array}$ & 12.1 & Familial & $\begin{array}{l}\text { Complex: WCST } \\
\text { Inhibition: CPT } \\
\text { Inhibition:Stroop } \\
\text { Color-Word } \\
\text { WM: Numbers } \\
\text { reversed test }\end{array}$ \\
\hline $\begin{array}{r}\text { Kavanaugh and } \\
\text { Holler (2014) }\end{array}$ & $\begin{array}{l}\text { Journal of Child \& } \\
\text { Adolescent Trauma }\end{array}$ & USA & $\begin{array}{l}\text { PTSS: } 17 \\
\text { TE: } 18 \\
\text { HC: } 18\end{array}$ & 15.5 & Familial & $\begin{array}{l}\text { Complex: WCST } \\
\text { Verbal fluency: } \\
\text { COWAT } \\
\text { Inhibition: Stroop } \\
\text { Color-Word } \\
\text { Shifting: TMT } \\
\text { WM: Sentence } \\
\text { repetition }\end{array}$ \\
\hline $\begin{array}{l}\text { Kavanaugh } \\
\text { et al. (2015) }\end{array}$ & $\begin{array}{l}\text { Applied } \\
\text { Neuropsychology: } \\
\text { Child }\end{array}$ & USA & $\begin{array}{l}\text { PTSS: } 49 \\
\text { HC: } 73\end{array}$ & 15.3 & Familial & $\begin{array}{l}\text { Complex: WCST } \\
\text { Verbal fluency: } \\
\text { COWAT } \\
\text { Inhibition: Stroop } \\
\text { Color-Word } \\
\text { Shifting: TMT } \\
\text { WM: Sentence } \\
\text { repetition }\end{array}$ \\
\hline $\begin{array}{l}\text { Malarbi et al. } \\
(2020)\end{array}$ & Child Neuropsychology & $\begin{array}{r}\text { Melbourne, } \\
\text { Australia }\end{array}$ & $\begin{array}{l}\text { PTSS: } 6 \\
\text { TE: } 10 \\
\text { HC: } 19\end{array}$ & 13.3 & $\begin{array}{l}\text { Non- } \\
\quad \text { familial }\end{array}$ & $\begin{array}{l}\text { Complex: } \\
\text { Contingency } \\
\text { naming test } \\
\text { Shifting: Category } \\
\text { switching fluency } \\
\text { WM: WISC-IV WM } \\
\text { index }\end{array}$ \\
\hline $\begin{array}{l}\text { Mueller et al. } \\
\qquad(2015)\end{array}$ & Journal of Adolescence & $\begin{array}{l}\text { Lira, } \\
\text { Northern } \\
\text { Uganda }\end{array}$ & $\begin{array}{l}\text { PTSS: } 20 \\
\text { HC: } 52\end{array}$ & 16.6 & Familial & $\begin{array}{l}\text { Inhibition: Stroop } \\
\text { Color-Word }\end{array}$ \\
\hline $\begin{array}{l}\text { Park et al. } \\
\text { (2014) }\end{array}$ & $\begin{array}{l}\text { Anxiety, Stress, \& } \\
\text { Coping }\end{array}$ & $\begin{array}{l}\text { Seoul, } \\
\text { Korea }\end{array}$ & $\begin{array}{l}\text { PTSS: } 26 \\
\text { TE: } 25 \\
\text { HC: } 30\end{array}$ & 12.4 & $\begin{array}{l}\text { Non- } \\
\text { familial }\end{array}$ & $\begin{array}{l}\text { Inhibition: Sustained } \\
\text { attention task } \\
\text { Inhibition: Flanker } \\
\text { WM: Divided } \\
\text { attention task } \\
\text { WM: Spatial WM task }\end{array}$ \\
\hline
\end{tabular}


Table 1. (Continued).

\begin{tabular}{|c|c|c|c|c|c|c|}
\hline Study & Journal & $\begin{array}{l}\text { Study } \\
\text { location }\end{array}$ & $\begin{array}{l}\text { Number of } \\
\text { participants }\end{array}$ & $\begin{array}{c}\text { Age } \\
\text { (mean) }\end{array}$ & $\begin{array}{l}\text { Trauma } \\
\text { type }\end{array}$ & $\begin{array}{l}\text { Executive function } \\
\text { subdomains and tasks }\end{array}$ \\
\hline $\begin{array}{l}\text { Samuelson } \\
\text { et al. (2010) }\end{array}$ & $\begin{array}{l}\text { Child } \\
\text { Neurospsychology }\end{array}$ & USA & $\begin{array}{l}\text { PTSS: } 27 \\
\text { HC: } 35\end{array}$ & 11.8 & Familial & $\begin{array}{l}\text { Complex: WCST } \\
\text { Complex: Tower of } \\
\text { London } \\
\text { Inhibition: Stroop } \\
\text { Color-Word } \\
\text { WM: Digit span } \\
\text { WM: Letter-number } \\
\text { sequencing }\end{array}$ \\
\hline Wu et al. (2010) & Neuroscience Letters & $\begin{array}{l}\text { Wenchuan, } \\
\text { China }\end{array}$ & $\begin{array}{l}\text { PTSS: } 9 \\
\text { HC: } 16\end{array}$ & 16.2 & $\begin{array}{l}\text { Non- } \\
\text { familial }\end{array}$ & Inhibition: Go/Go-No \\
\hline
\end{tabular}

Abbreviations: PTSS = Posttraumatic stress symptoms, TE = traumatic experience, $\mathrm{HC}=$ healthy controls, $\mathrm{WM}=$ working memory, WCST $=$ Wisconsin Card Sorting Test, CPT = continuous performance test, COWAT = Controlled Oral Word Association Test, TMT = Trail making test, WISC = Wechsler Intelligence Scales for Children. Trauma types: Familial $=$ child maltreatment or parental loss, Non-familial $=$ accident or disaster, Sexual $=$ child sexual abuse by a family member or someone else.

\section{Meta-analysis}

\section{Executive functions in PTSS vs healthy controls}

We first compared executive functioning in children with PTSS to healthy controls. The forest plot for the results are presented in Figure 2, and Table 2 presents a summary of the findings. There was strong heterogeneity among the 55 outcomes included in the metaanalysis (chi-square $(52)=334.62, \mathrm{p}<.001$; tau $=0.67 ; I^{2}=84 \%(95 \% \mathrm{CI}=80 \%$ to $88 \%)$.

Similarly, none of the executive function subdomains was homogenous. When examined on a global level across all executive function tasks and measures, children with PTSS had significantly worse executive functioning compared to non-trauma exposed healthy controls (SMD $=-0.57$ (95\% CI $=-0.77,-0.37), \mathrm{p}<.001)$. The effect sizes between the five executive function subdomains were not significantly different from each other $(\mathrm{Q}=7.18(4), p=.13)$. Verbal fluency had the largest effect size (SMD of -1.45 ), followed by working memory and complex executive function measures (SMD of -0.59 and -0.55 respectively). The smallest effect sizes were seen for inhibition and shifting (SMD of -0.33 and -0.48 respectively). These group differences were significant for all investigated subdomains.

\section{Executive functions in PTSS versus traumatic events}

Second, we compared executive functioning in children with PTSS to children exposed to traumatic events but without PTSS. Six of the included studies in this meta-analysis included a comparison group of youth that were exposed to traumatic events but who did not develop PTSS. Such a comparison is central in the understanding of whether it is the symptoms of psychopathology or the traumatic event in itself that is associated with lower executive functioning.

The results of this meta-analysis are presented in Figure 3, and summarized in Table 2. There was high heterogeneity across the 24 included effect sizes (chi-square $(23)=74.63, \mathrm{p}<.001 ;$ tau $=0.56 ; I^{2}=69 \%$ (95\% CI $=53 \%$ to $\left.80 \%\right)$. However, the complex and fluency executive functions subdomains were the only two which showed significant heterogeneity. When compared to children with traumatic experiences, but without PTSS, children with PTSS had overall significantly worse executive functioning 


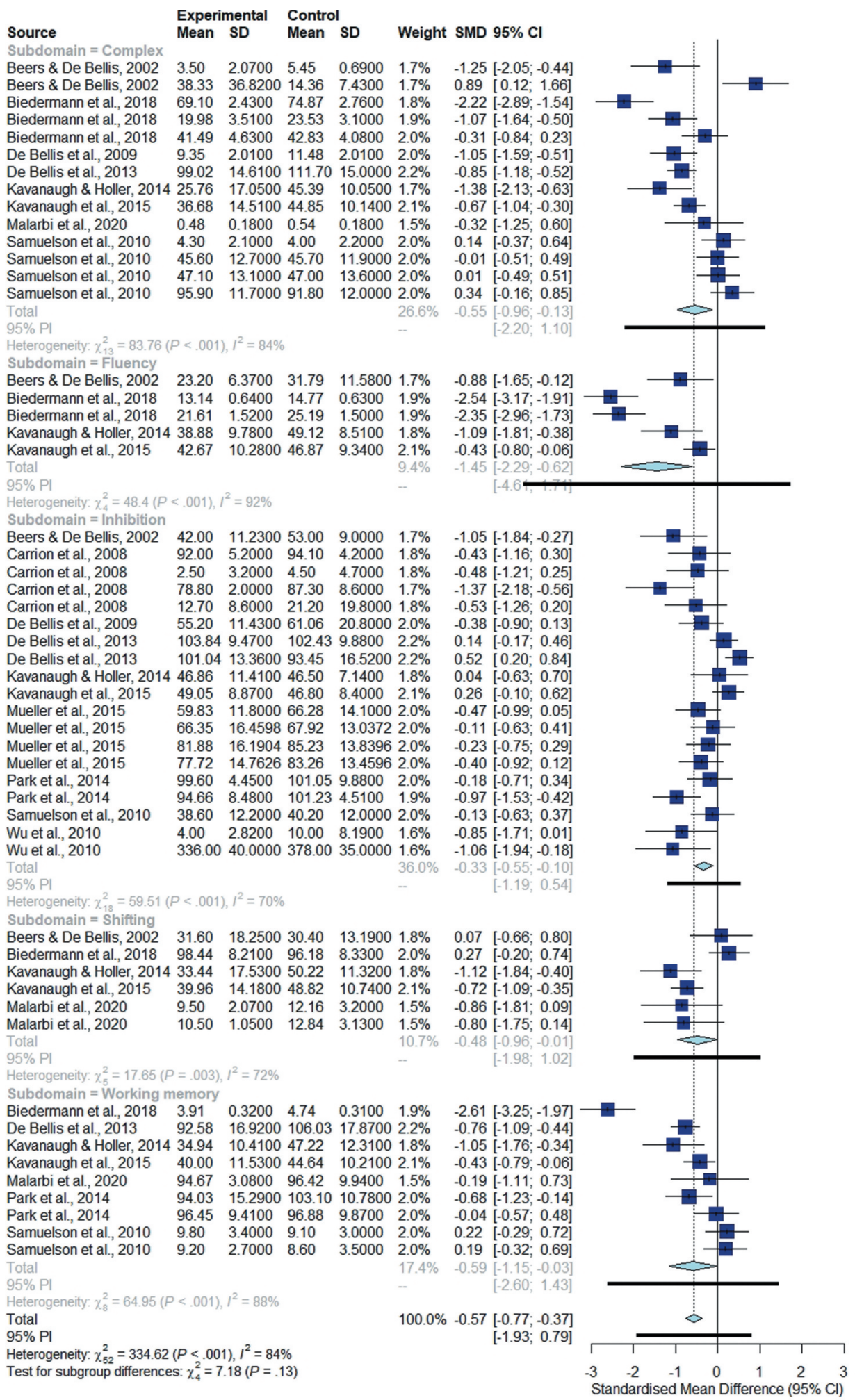

Figure 2. Forest plot from meta-analysis on executive functions in children with PTSS vs. healthy controls. 


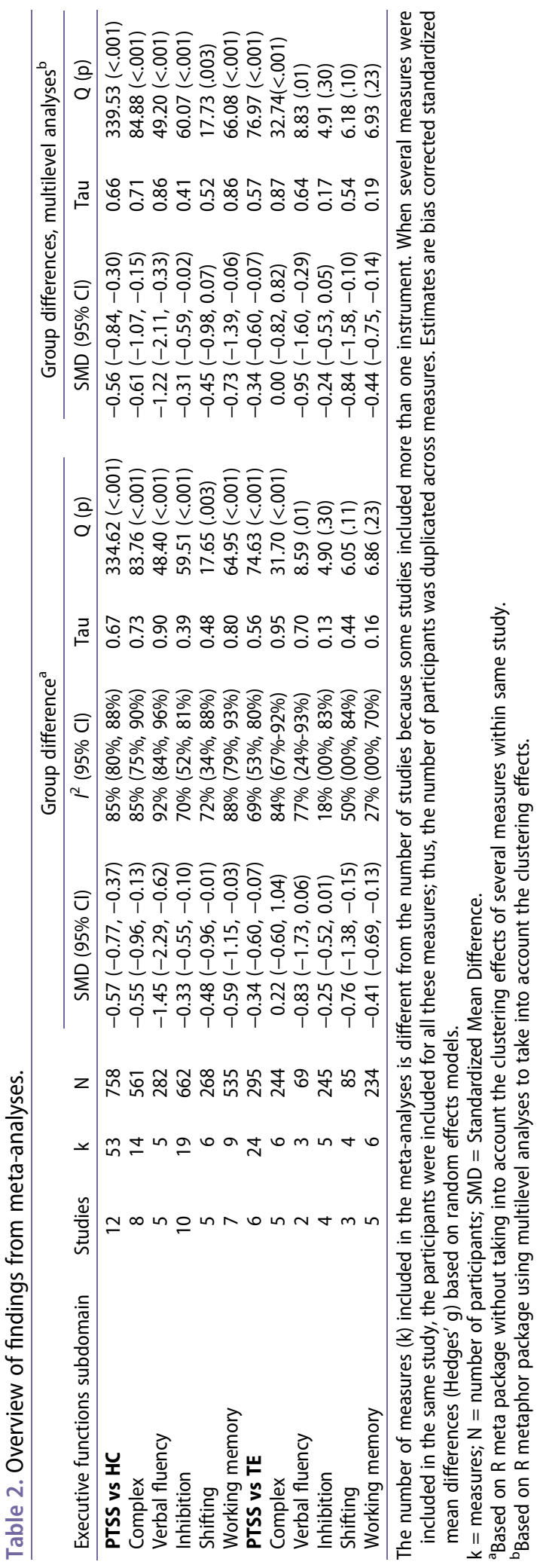




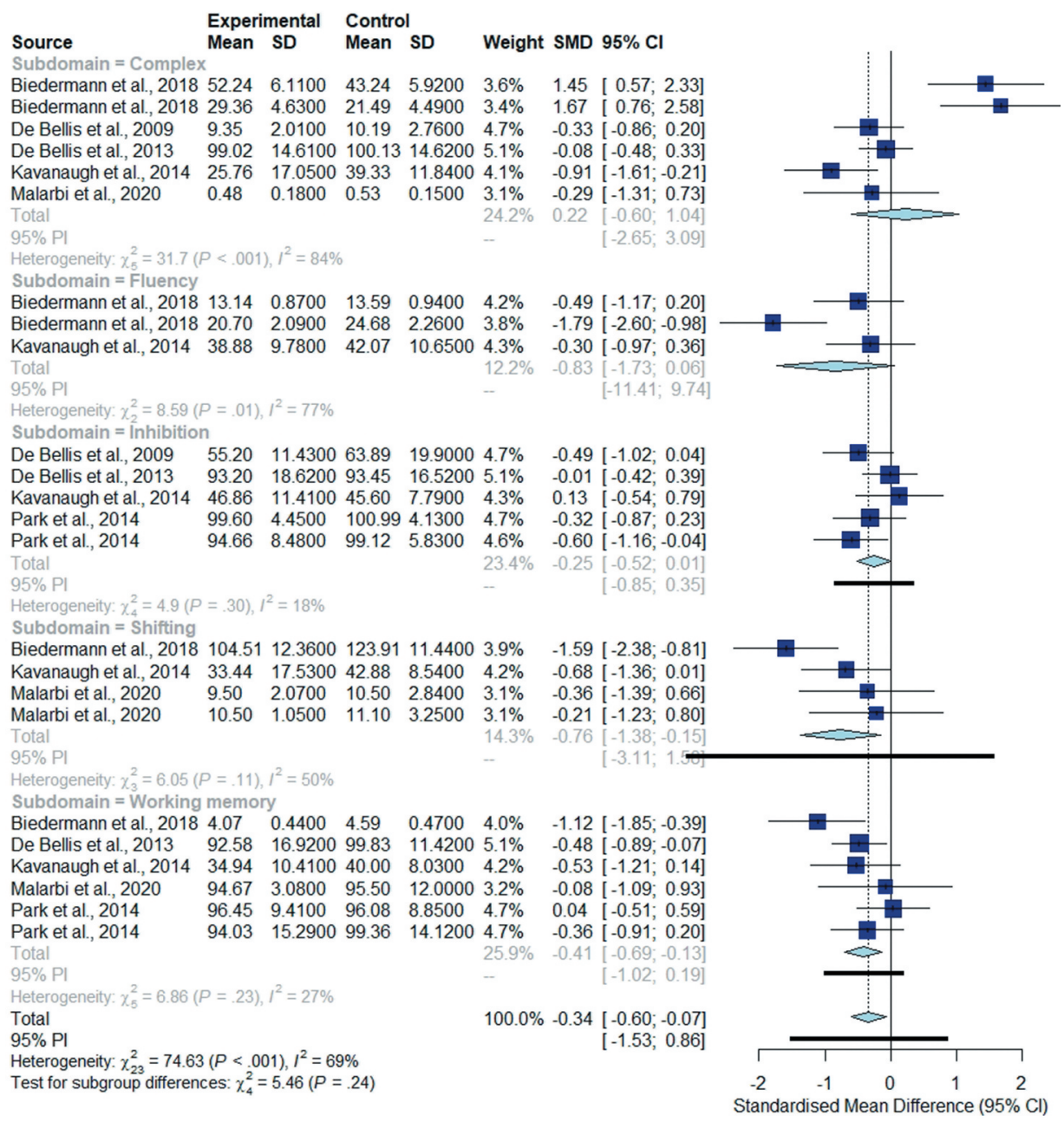

Figure 3. Forest plot from meta-analysis on executive functions in children with PTSS vs. children with traumatic experiences but without PTSS.

$(\mathrm{SMD}=-0.34(95 \% \mathrm{CI}=-0.60,-0.07, p=.01)$. There were no significant differences in effect sizes between the five executive function subdomains $(\mathrm{Q}=5.46(4), p=.24)$. Children and adolescents with PTSS did significantly worse than trauma-exposed children without PTSS in the two executive function subdomains of shifting and working memory (SMD $=-0.76$ and -0.41 , respectively), but not on complex tasks, fluency or inhibition.

\section{Covariates}

Age $(B=-0.10(95 \% \mathrm{CI}=-0.19,-0.09), p=.04)$, but not publication year $(B=-0.04$ (95\% CI $=-0.08,0.00), p=.06)$, was significantly related to the overall difference in executive functioning between children with PTSS and healthy controls. In the analyses 
of children with PTSS and children exposed to traumatic events, neither age $(B=-0.01$ $(95 \% \mathrm{CI}=-0.15,0.12), p=.85)$, nor publication year $(B=0.01(95 \% \mathrm{CI}=-0.09,0.11)$, $p=.89)$ were significantly related to the overall group difference.

\section{Multilevel analyses}

Sensitivity analyses that consider the inclusion of several measures from the same study are presented in Table 2. There are no major differences between the results from these multilevel analyses and the results from the main analyses presented above.

\section{Bias evaluation}

There were risks of bias in all but one of the included studies. Detailed results from the assessment of bias are shown in Table S1. Out of the 12 studies, five did not report whether the groups were similar or different in socioeconomic status and one reported that there was a difference, and these studies therefore had a risk of selection bias. For seven of the 12 studies, it is natural to assume that participants had knowledge of their clinical status and the focus of the study and that the performance bias therefore was high. One study reported that the test administrator was unblinded, while five other studies did not report whether the administrator was blinded or not to clinical status, and therefore had possible detection bias. None of the studies showed risk of attrition bias, and only two studies showed risk of reporting bias, as only results for composite scores were reported. We did not find other bias risks in any of the studies. The funnel plots did not indicate serious publication bias, but did support that there was great heterogeneity among the studies (Figures S1 and S2).

\section{Discussion}

The present systematic review and meta-analysis indicate that children with PTSS have overall poorer executive functioning compared to healthy controls. The effect sizes varied between small to large for the different executive function subdomains complex tasks, verbal fluency, inhibition, shifting and working memory, but were not significantly different from each other. Thus, the results did not provide evidence for diversity in executive function impairment in children with PTSS, at least across the subdomains included in the present analysis. Similarly, analyses comparing children with traumatic experiences with and without PTSS showed overall poorer executive functioning in the PTSS group, albeit no significant differences in the effects across the executive function subdomains. The findings from the present meta-analysis confirm the already documented association between childhood trauma and poorer executive functioning (e.g., (Augusti \& Melinder, 2013; DePrince et al., 2009; Lewis et al., 2007), see (Malarbi et al., 2017; Op den Kelder et al., 2018) for meta-analyses). In addition, the present meta-analysis expands on previous knowledge by indicating that the differences in executive functioning depend on the development of PTSS after the trauma. 
Being exposed to trauma and presenting with PTSS was associated with poorer executive functioning compared to non-traumatized healthy controls. Beyond this overall difference across all executive function tasks and measures, no significant difference in effect sizes was found between the various executive function subdomains. This finding may suggest that there is not one or only a few subdomains that are negatively affected by trauma and PTSS, but rather that impairments in several subdomains of executive function may be associated with trauma symptoms. It is possible that significant differences between the subdomains could have been found if more studies were available for inclusion in the meta-analysis. When testing each subdomain separately, we observed the largest effect size for verbal fluency, but the differences were significant for all investigated domain. Previous meta-analyses have found broad deficits in cognition (Malarbi et al., 2017; Masson et al., 2015) and executive functions (Op den Kelder et al., 2018) in trauma-exposed youth compared to non-traumatized individuals, and the present study expands on this finding by testing specific subdomains of executive functions in children with PTSS and finding overall poorer executive functioning compared to healthy controls. Moreover, we found a negative association between age of participants and the overall difference in executive functioning between children with PTSS and healthy controls, possibly indicating greater vulnerability at younger ages or that the effect reduces over time, but this result should be interpreted with caution given the small number and cross-sectional nature of available studies.

A second objective of the present meta-analysis was to investigate whether presenting with PTSS compared to the absence of PTSS after childhood trauma is associated with different scores on executive functioning tasks, and if so if this is a global difference or specific to certain executive function subdomains. Similar to the comparison between children with PTSS and healthy controls, albeit with a smaller effect size, we found that children with traumatic experiences and PTSS showed overall poorer executive functioning than children with traumatic experiences without PTSS. Also here, there were no significant differences in the effects across the executive function subdomains. When testing each subdomain separately, only the shifting and working memory domains showed significant differences between traumatized children with and without PTSS, possibly due to the relatively small number of studies and outcome comparisons available for some of the subdomains in these analyses.

The present meta-analysis confirmed previous findings on the association between trauma and executive functioning, as well as the additional toll with which PTSS adds to difficulties in traumatized children's cognition. However, the question as to whether some executive function subdomains are more negatively affected than others was not confirmed. A possible explanation of the lack of differences among specific subdomains of executive functioning may be the heterogeneity in tests and measures used to map the various subdomains included in our analyses. Previous studies have indicated that executive function subdomains are differently associated with trauma-exposure and PTSS. For instance, in a study on maltreated children, spatial working memory was the one domain mostly impaired compared to the other domains (Augusti \& Melinder, 2013). In another study, on traumatized adolescents, set shifting turned out as the function most strongly associated with PTSS, but only in boys (Melinder et al., 2015). As discussed further below, most studies on the associations between trauma, PTSS and 
executive functioning are based on relatively small and heterogeneous samples, rendering it difficult to draw firm conclusions. The present meta-analysis may therefore shed new light on previous findings pertaining to specific executive functions being more or less affected by trauma-related stress reactions.

Although we in this meta-analysis comprehensively assessed executive functioning and specific executive function subdomains in children with PTSS compared to healthy controls and traumatized children without PTSS, some caveats merit consideration. First, most of the available studies have included relatively small samples. Second, a variety of tasks and measures have been used to assess executive functions in children with PTSS. Although the tests used in the studies included in the present meta-analysis are generally well-established and psychometrically sound, they are not necessarily developed to test the exact subdomains in the empirically based model by Miyake, Friedman and colleagues (Friedman \& Miyake, 2017; Miyake et al., 2000), which the present study is based on. Moreover, not all measures were described in detail in the original studies, further complicating the categorization into subdomains. As such, some variance in our subdomain results might be ascribed to that the tests and measures included do not easily map onto single subdomains in this model. Third, we did not investigate timing or chronicity effects of the traumatic events behind PTSS on executive functioning. Previous studies indicate that abuse taking place early in life or over a prolonged period has a more severe impact on cognitive functioning than abuse with later onset or abuse, which is not chronic (Cowell et al., 2015). Fourth, most of the studies included in the present meta-analysis included samples with children exposed to familial trauma, also known as child maltreatment. Only a minority of the studies included samples exposed to traumatic events outside the family and which does not involve interpersonal trauma. There is a scarcity of studies on the association between non-familial trauma, such as accidents and natural disasters, and executive functioning and later development of PTSS. The relative imbalance between study samples when it comes to type of trauma exposure precluded the use of trauma type as a co-variate in the present meta-analysis. Previous studies on the prevalence of PTSD after trauma suggest that non-familial trauma results in lower levels of PTSD (Alisic et al., 2014), and we speculate that non-familiar trauma may also be associated with relatively smaller or fewer difficulties with executive functioning.

Future research should aim to further our understanding of the roles of timing and duration of trauma and of specific types of trauma in cognitive and executive functioning in children (see e.g., McLaughlin et al., 2020; Nolin \& Ethier, 2007). Moreover, the present meta-analysis did not include executive functioning tasks with emotional valence, and future studies should further disentangle whether different patterns of associations are revealed when emotional information is embedded in executive functioning tasks ("hot" executive functions; Zelazo \& Carlson, 2012). Such tasks have been considered more ecologically valid, as emotion regulation functions may be central for the development of psychopathology after trauma (Aupperle et al., 2012; Briggs-Gowan et al., 2015; Sætren et al., 2021; Schweizer et al., 2019; Shackman et al., 2007). Future studies should also test how executive functioning in children with post-traumatic stress reactions relates to daily life and school functioning, as well as whether executive functioning moderates treatment outcomes. 


\section{Disclosure statement}

No potential conflict of interest was reported by the author(s).

\section{Funding}

C.K.T. was supported by the Research Council of Norway [\#223273, \#288083, \#301767] and the South-Eastern Norway Regional Health Authority [\#2019069, \#2021070, \#500189]. Martin Ostenfeldt Trøstheim at the Department of Psychology, University of Oslo gave invaluable statistical support.

\section{ORCID}

Egil Nygaard (D) http://orcid.org/0000-0002-8865-4265

Else-Marie Augusti (D) http://orcid.org/0000-0002-2074-6198

Christian K. Tamnes (D) http://orcid.org/0000-0002-9191-6764

\section{Data availability statement}

The data used in the meta-analyses is available in the Supplementary Materials and at the Open Science Framework, https://osf.io/9nujs/.

\section{References}

Akshoomoff, N., Brown, T. T., Bakeman, R., \& Hagler, D. J. (2018). Developmental differentiation of executive functions on the NIH toolbox cognition battery. Neuropsychology, 32(7), 777-783. https://doi.org/10.1037/neu0000476

Alisic, E., Zalta, A. K., Van Wesel, F., Larsen, S. E., Hafstad, G. S., Hassanpour, K., \& Smid, G. E. (2014). Rates of post-traumatic stress disorder in trauma-exposed children and adolescents: Meta-analysis. British Journal of Psychiatry, 204(5), 335-340. https://doi.org/10.1192/bjp.bp.113.131227

Appleyard, K., Egeland, B., Dulmen, M. H. M., \& Alan Sroufe, L. (2005). When more is not better: The role of cumulative risk in child behavior outcomes. Journal of Child Psychology and Psychiatry, 46(3), 235-245. https://doi.org/10.1111/j.1469-7610.2004.00351.x

Augusti, E.-M., \& Melinder, A. (2013). Maltreatment is associated with specific impairments in executive functions: A pilot study: Executive functions in maltreated children. Journal of Traumatic Stress, 26(6), 780-783. https://doi.org/10.1002/jts.21860

Aupperle, R. L., Melrose, A. J., Stein, M. B., \& Paulus, M. P. (2012). Executive function and PTSD: Disengaging from trauma. Neuropharmacology, 62(2), 686-694. https://doi.org/10.1016/j.neuro pharm.2011.02.008

Balduzzi, S., Rücker, G., \& Schwarzer, G. (2019). How to perform a meta-analysis with R: A practical tutorial. Evidence Based Mental Health, 22(4), 153-160. https://doi.org/10.1136/ ebmental-2019-300117

Barrera, M., Calderón, L., \& Bell, V. (2013). The cognitive impact of sexual abuse and PTSD in children: A neuropsychological study. Journal of Child Sexual Abuse, 22(6), 625-638. https:// doi.org/10.1080/10538712.2013.811141

Baum, G. L., Cui, Z., Roalf, D. R., Ciric, R., Betzel, R. F., Larsen, B., Cieslak, M., Cook, P. A., Xia, C. H., Moore, T. M., Ruparel, K., Oathes, D. J., Alexander-Bloch, A. F., Shinohara, R. T., Raznahan, A., Gur, R. E., Gur, R. C., Bassett, D. S., \& Satterthwaite, T. D. (2020). Development of structure-function coupling in human brain networks during youth. Proceedings of the National Academy of Sciences, 117(1), 771-778. https://doi.org/10.1073/pnas.1912034117 
Beers, S. R., \& De Bellis, M. D. (2002). Neuropsychological function in children with maltreatment-related posttraumatic stress disorder. American Journal of Psychiatry, 159(3), 483-486. https://doi.org/10.1176/appi.ajp.159.3.483

Biederman, J., Monuteaux, M. C., Doyle, A. E., Seidman, L. J., Wilens, T. E., Ferrero, F., Morgan, C. L., \& Faraone, S. V. (2004). Impact of executive function deficits and Attention-Deficit/Hyperactivity Disorder (ADHD) on academic outcomes in children. Journal of Consulting and Clinical Psychology, 72(5), 757-766. https://doi.org/10.1037/0022006X.72.5.757

Biedermann, S. V., Meliss, S., Simmons, C., Nöthling, J., Suliman, S., \& Seedat, S. (2018). Sexual abuse but not posttraumatic stress disorder is associated with neurocognitive deficits in South African traumatized adolescents. Child Abuse \& Neglect, 80, 257-267. https://doi.org/10.1016/j. chiabu.2018.04.003

Briggs-Gowan, M. J., Pollak, S. D., Grasso, D., Voss, J., Mian, N. D., Zobel, E., McCarthy, K. J., Wakschlag, L. S., \& Pine, D. S. (2015). Attention bias and anxiety in young children exposed to family violence. Journal of Child Psychology and Psychiatry, 56(11), 1194-1201. https://doi.org/ $10.1111 /$ jcpp. 12397

Carrion, V. G., Garrett, A., Menon, V., Weems, C. F., \& Reiss, A. L. (2008). Posttraumatic stress symptoms and brain function during a response-inhibition task: An fMRI study in youth. Depression and Anxiety, 25(6), 514-526. https://doi.org/10.1002/da.20346

Christ, C., De Waal, M. M., Dekker, J. J. M., Van Kuijk, I., van Schaik, D. J. F., Kikkert, M. J., Goudriaan, A. E., Beekman, A. T. F., \& Messman-Moore, T. L. (2019). Linking childhood emotional abuse and depressive symptoms: The role of emotion dysregulation and interpersonal problems. PLOS ONE, 14(2), e0211882. https://doi.org/10.1371/journal.pone.0211882

Cowell, R. A., Cicchetti, D., Rogosch, F. A., \& Toth, S. L. (2015). Childhood maltreatment and its effect on neurocognitive functioning: Timing and chronicity matter. Development and Psychopathology, 27(2), 521-533. https://doi.org/10.1017/S0954579415000139

Danzi, B. A., \& La Greca, A. M. (2017). Optimizing clinical thresholds for PTSD: Extending the DSM-5 preschool criteria to school-age children. International Journal of Clinical and Health Psychology, 17(3), 234-241. https://doi.org/10.1016/j.ijchp.2017.07.001

De Bellis, M. D., Hooper, S. R., Spratt, E. G., \& Woolley, D. P. (2009). Neuropsychological findings in childhood neglect and their relationships to pediatric PTSD. Journal of the International Neuropsychological Society, 15(6), 868-878. https://doi.org/10.1017/S1355617709990464

De Bellis, M. D., Woolley, D. P., \& Hooper, S. R. (2013). Neuropsychological findings in pediatric maltreatment: Relationship of PTSD, dissociative symptoms, and abuse/neglect indices to neurocognitive outcomes. Child Maltreatment, 18(3), 171-183. https://doi.org/10.1177/ 1077559513497420

DePrince, A. P., Weinzierl, K. M., \& Combs, M. D. (2009). Executive function performance and trauma exposure in a community sample of children. Child Abuse \& Neglect, 33(6), 353-361. https://doi.org/10.1016/j.chiabu.2008.08.002

Donati, G., Meaburn, E. L., \& Dumontheil, I. (2019). The specificity of associations between cognition and attainment in English, maths and science during adolescence. Learning and Individual Differences, 69, 84-93. https://doi.org/10.1016/j.lindif.2018.11.012

Dvir, Y., Ford, J. D., Hill, M., \& Frazier, J. A. (2014). Childhood maltreatment, emotional dysregulation, and psychiatric comorbidities. Harvard Review of Psychiatry, 22(3), 149-161. https://doi.org/10.1097/HRP.000000000000014

Felitti, V. J. (2002). The relation between adverse childhood experiences and adult health: Turning gold into lead. The Permanente Journal, 6(1), 44-47. https://www.ncbi.nlm.nih.gov/pmc/arti cles/PMC6220625/pdf/permj-6-1-44.pdf

Fiske, A., \& Holmboe, K. (2019). Neural substrates of early executive function development. Developmental Review, 52, 42-62. https://doi.org/10.1016/j.dr.2019.100866

Friedman, N. P., \& Miyake, A. (2017). Unity and diversity of executive functions: Individual differences as a window on cognitive structure. Cortex; a Journal Devoted to the Study of the Nervous System and Behavior, 86, 186-204. https://doi.org/10.1016/j.cortex.2016.04.023 
Geeraert, B. L., Lebel, R. M., \& Lebel, C. (2019). A multiparametric analysis of white matter maturation during late childhood and adolescence. Human Brain Mapping, 40(15), 4345-4356. https://onlinelibrary.wiley.com/doi/full/10.1002/hbm.24706

Gilbert, R., Widom, C. S., Browne, K., Fergusson, D., Webb, E., \& Janson, S. (2009). Burden and consequences of child maltreatment in high-income countries. The Lancet, 373(9657), 68-81. https://doi.org/10.1016/S0140-6736(08)61706-7

Goddings, A.-L., Roalf, D., Lebel, C., \& Tamnes, C. K. (2021). Development of white matter microstructure and executive functions during childhood and adolescence: A review of diffusion MRI studies. Developmental Cognitive Neuroscience, 51, 101008. https://doi.org/10.1016/j. dcn.2021.101008

Hartung, J., Engelhardt, L. E., Thibodeaux, M. L., Harden, K. P., \& Tucker-Drob, E. M. (2020). Developmental transformations in the structure of executive functions. Journal of Experimental Child Psychology, 189, 104681. https://doi.org/10.1016/j.jecp.2019.104681

Heleniak, C., Jenness, J. L., Vander Stoep, A., McCauley, E., \& McLaughlin, K. A. (2016). Childhood maltreatment exposure and disruptions in emotion regulation: A transdiagnostic pathway to adolescent internalizing and externalizing psychopathology. Cognitive Therapy and Research, 40(3), 394-415. https://doi.org/10.1007/s10608-015-9735-z

Higgins, J. P. T., Altman, D. G., Gotzsche, P. C., Juni, P., Moher, D., Oxman, A. D., Savovic, J., Schulz, K. F., Weeks, L., \& Sterne, J. A. C., \& Cochrane Bias Methods Group, \& Cochrane Statistical Methods Group. (2011). The cochrane collaboration's tool for assessing risk of bias in randomised trials. BMJ, 343 (oct182), d5928-d5928. https://doi.org/10.1136/bmj.d5928

Huizinga, M., Dolan, C. V., \& Van der Molen, M. W. (2006). Age-related change in executive function: Developmental trends and a latent variable analysis. Neuropsychologia, 44(11), 2017-2036. https://doi.org/10.1016/j.neuropsychologia.2006.01.010

Johnson, D., Policelli, J., Li, M., Dharamsi, A., Hu, Q., Sheridan, M. A., McLaughlin, K. A., \& Wade, M. (2021). Associations of early-life threat and deprivation with executive functioning in childhood and adolescence: A systematic review and meta-analysis. JAMA Pediatrics, e212511. https://doi.org/10.1001/jamapediatrics.2021.2511

Kavanaugh, B., \& Holler, K. (2014). Executive, emotional, and language functioning following childhood maltreatment and the influence of pediatric PTSD. Journal of Child \& Adolescent Trauma, 7(2), 121-130. https://doi.org/10.1007/s40653-014-0014-z

Kavanaugh, B., Holler, K., \& Selke, G. (2015). A neuropsychological profile of childhood maltreatment within an adolescent inpatient sample. Applied Neuropsychology: Child, 4(1), 9-19. https:// doi.org/10.1080/21622965.2013.789964

Kavanaugh, B. C., Dupont-Frechette, J. A., Jerskey, B. A., \& Holler, K. A. (2017). Neurocognitive deficits in children and adolescents following maltreatment: Neurodevelopmental consequences and neuropsychological implications of traumatic stress. Applied Neuropsychology: Child, 6(1), 64-78. https://doi.org/10.1080/21622965.2015.1079712

Lebel, C., \& Beaulieu, C. (2011). Longitudinal development of human brain wiring continues from childhood into adulthood. Journal of Neuroscience, 31(30), 10937-10947. https://doi.org/10. 1523/JNEUROSCI.5302-10.2011

Lee, K., Bull, R., \& Ho, R. M. H. (2013). Developmental changes in executive functioning. Child Development, 84(6), 1933-1953. https://doi.org/10.1111/cdev.12096

Lehto, J. E., Juujärvi, P., Kooistra, L., \& Pulkkinen, L. (2003). Dimensions of executive functioning: Evidence from children. British Journal of Developmental Psychology, 21(1), 59-80. https://doi. org/10.1348/026151003321164627

Lewis, E. E., Dozier, M., Ackerman, J., \& Sepulveda-Kozakowski, S. (2007). The effect of placement instability on adopted children's inhibitory control abilities and oppositional behavior. Developmental Psychology, 43(6), 1415-1427. https://doi.org/10.1037/0012-1649. 43.6.1415

Malarbi, S., Abu-Rayya, H. M., Muscara, F., \& Stargatt, R. (2017). Neuropsychological functioning of childhood trauma and post-traumatic stress disorder: A meta-analysis. Neuroscience \&Biobehavioral Reviews, 72, 68-86. https://doi.org/10.1016/j.neubiorev.2016.11.004 
Malarbi, S. T., Muscara, F., Barnett, P. L. J., Palmer, C. S., \& Stargatt, R. (2020). Post-traumatic stress symptoms and cognition in children exposed to motor vehicle accident trauma. Child Neuropsychology, 26(4), 560-575. https://doi.org/10.1080/09297049.2019.1700223

Masson, M., Bussières, E.-L., East-Richard, C., R-Mercier, A., \& Cellard, C. (2015). Neuropsychological profile of children, adolescents and adults experiencing maltreatment: A meta-analysis. The Clinical Neuropsychologist, 29(5), 573-594. https://doi.org/10.1080/ 13854046.2015.1061057

McClelland, M. M., \& Cameron, C. E. (2012). Self-regulation in early childhood: Improving conceptual clarity and developing ecologically valid measures. Child Development Perspectives, 6(2), 136-142. https://doi.org/10.1111/j.1750-8606.2011.00191.x

McLaughlin, K. A., Colich, N. L., Rodman, A. M., \& Weissman, D. G. (2020). Mechanisms linking childhood trauma exposure and psychopathology: A transdiagnostic model of risk and resilience. BMC Medicine, 18(1). https://doi.org/10.1186/s12916-020-01561-6

McLaughlin, K. A., Koenen, K. C., Hill, E. D., Petukhova, M., Sampson, N. A., Zaslavsky, A. M., \& Kessler, R. C. (2013). Trauma exposure and posttraumatic stress disorder in a national sample of adolescents. Journal of the American Academy of Child \& Adolescent Psychiatry, 52(8), 815-830. e14. https://doi.org/10.1016/j.jaac.2013.05.011

Melinder, A., Augusti, E.-M., Matre, M., \& Endestad, T. (2015). Associations between executive functions and long-term stress reactions after extreme trauma: A two-year follow-up of the Utøya survivors. Psychological Trauma: Theory, Research, Practice, and Policy, 7(6), 583-590. https://doi.org/10.1037/tra0000048

Miyake, A., Friedman, N. P., Emerson, M. J., Witzki, A. H., Howerter, A., \& Wager, T. D. (2000). The unity and diversity of executive functions and their contributions to complex "Frontal Lobe" tasks: A latent variable analysis. Cognitive Psychology, 41(1), 49-100. https://doi.org/10. 1006/cogp.1999.0734

Moher, D., Liberati, A., Tetzlaff, J., \& Altman, D. G., \& for the PRISMA Group. (2009). Preferred reporting items for systematic reviews and meta-analyses: The PRISMA statement. BMJ, 339 (jul211), b2535-b2535. https://doi.org/10.1136/bmj.b2535

Mueller, S. C., Baudoncq, R., \& De Schryver, M. (2015). The effect of parental loss on cognitive and affective interference in adolescent boys from a post-conflict region. Journal of Adolescence, 42, 11-19. https://doi.org/10.1016/j.adolescence.2015.03.018

Nolin, P., \& Ethier, L. (2007). Using neuropsychological profiles to classify neglected children with or without physical abuse. Child Abuse \& Neglect, 31(6), 631-643. https://doi.org/10.1016/j. chiabu.2006.12.009

Norbom, L. B., Ferschmann, L., Parker, N., Agartz, I., Andreassen, O. A., Paus, T., Westlye, L. T., \& Tamnes, C. K. (2021). New insights into the dynamic development of the cerebral cortex in childhood and adolescence: Integrating macro- and microstructural MRI findings. Progress in Neurobiology, 204, 102109. https://doi.org/10.1016/j.pneurobio.2021.102109

Op den Kelder, R., Van den Akker, A. L., Geurts, H. M., Lindauer, R. J. L., \& Overbeek, G. (2018). Executive functions in trauma-exposed youth: A meta-analysis. European Journal of Psychotraumatology, 9(1), 1450595. https://doi.org/10.1080/20008198.2018.1450595

Palacios-Barrios, E. E., \& Hanson, J. L. (2019). Poverty and self-regulation: Connecting psychosocial processes, neurobiology, and the risk for psychopathology. Comprehensive Psychiatry, 90, 52-64. https://doi.org/10.1016/j.comppsych.2018.12.012

Park, S., Kim, B.-N., Choi, N.-H., Ryu, J., McDermott, B., Cobham, V., Song, S.-H., Kim, J.-W., Shin, M.-S., Yoo, H.-J., \& Cho, S.-C. (2014). The effect of persistent posttraumatic stress disorder symptoms on executive functions in preadolescent children witnessing a single incident of death. Anxiety, Stress, \& Coping, 27(3), 241-252. https://doi.org/10.1080/10615806.2013. 853049

Pechtel, P., \& Pizzagalli, D. A. (2011). Effects of early life stress on cognitive and affective function: An integrated review of human literature. Psychopharmacology, 214(1), 55-70. https://doi.org/ $10.1007 / \mathrm{s} 00213-010-2009-2$ 
Perkins, S., \& Graham-Bermann, S. (2012). Violence exposure and the development of school-related functioning: Mental health, neurocognition, and learning. Aggression and Violent Behavior, 17(1), 89-98. https://doi.org/10.1016/j.avb.2011.10.001

Prencipe, A., Kesek, A., Cohen, J., Lamm, C., Lewis, M. D., \& Zelazo, P. D. (2011). Development of hot and cool executive function during the transition to adolescence. Journal of Experimental Child Psychology, 108(3), 621-637. https://doi.org/10.1016/j.jecp.2010.09.008

Sætren, S. S., Augusti, E.-M., \& Hafstad, G. S. (2021). Affective inhibitory control and risk for internalizing problems in adolescents exposed to child maltreatment: A population-based study. Journal of Abnormal Psychology, 130(2), 113-125. https://doi.org/10.1037/abn0000582

Saigh, P. A., Yasik, A. E., Oberfield, R. A., Halamandaris, P. V., \& Bremner, J. D. (2006). The intellectual performance of traumatized children and adolescents with or without posttraumatic stress disorder. Journal of Abnormal Psychology, 115(2), 332-340. https://doi.org/10.1037/0021843X.115.2.332

Samuelson, K. W., Krueger, C. E., Burnett, C., \& Wilson, C. K. (2010). neuropsychological functioning in children with posttraumatic stress disorder. Child Neuropsychology, 16(2), 119-133. https://doi.org/10.1080/09297040903190782

Schoeman, R., Carey, P., \& Seedat, S. (2009). Trauma and posttraumatic stress disorder in South African adolescents: A case-control study of cognitive deficits. Journal of Nervous \& Mental Disease, 197(4), 244-250. https://doi.org/10.1097/NMD.0b013e31819d9533

Schweizer, S., Gotlib, I. H., \& Blakemore, S.-J. (2020). The role of affective control in emotion regulation during adolescence. Emotion, 20(1), 80-86. https://doi.org/10.1037/emo0000695

Schweizer, S., Parker, J., Leung, J. T., Griffin, C., \& Blakemore, S.-J. (2020). Age-related differences in affective control and its association with mental health difficulties. Development and Psychopathology, 32(1), 329-341. https://doi.org/10.1017/S0954579419000099

Schweizer, S., Samimi, Z., Hasani, J., Moradi, A., Mirdoraghi, F., \& Khaleghi, M. (2017). Improving cognitive control in adolescents with post-traumatic stress disorder (PTSD). Behaviour Research and Therapy, 93, 88-94. https://doi.org/10.1016/j.brat.2017.03.017

Schweizer, S., Satpute, A. B., Atzil, S., Field, A. P., Hitchcock, C., Black, M., Barrett, L. F., \& Dalgleish, T. (2019). The impact of affective information on working memory: A pair of meta-analytic reviews of behavioral and neuroimaging evidence. Psychological Bulletin, 145 (6), 566-609. https://doi.org/10.1037/bul0000193

Scott, J. C., Matt, G. E., Wrocklage, K. M., Crnich, C., Jordan, J., Southwick, S. M., Krystal, J. H., \& Schweinsburg, B. C. (2015). A quantitative meta-analysis of neurocognitive functioning in posttraumatic stress disorder. Psychological Bulletin, 141(1), 105-140. https://doi.org/10.1037/a0038039

Scrimin, S., Axia, G., Capello, F., Moscardino, U., Steinberg, A. M., \& Pynoos, R. S. (2006). Posttraumatic reactions among injured children and their caregivers 3 months after the terrorist attack in Beslan. Psychiatry Research, 141(3), 333-336. https://doi.org/10.1016/j.psychres.2005.11.004

Shackman, J. E., Shackman, A. J., \& Pollak, S. D. (2007). Physical abuse amplifies attention to threat and increases anxiety in children. Emotion, 7(4), 838-852. https://doi.org/10.1037/1528-3542.7.4.838

Sterne, J. A. C., Sutton, A. J., Ioannidis, J. P. A., Terrin, N., Jones, D. R., Lau, J., Carpenter, J., Rucker, G., Harbord, R. M., Schmid, C. H., Tetzlaff, J., Deeks, J. J., Peters, J., Macaskill, P., Schwarzer, G., Duval, S., Altman, D. G., Moher, D., \& Higgins, J. P. T. (2011). Recommendations for examining and interpreting funnel plot asymmetry in meta-analyses of randomised controlled trials. BMJ, 343(jul22 1), d4002-d4002. https://doi.org/10.1136/bmj.d4002

Tamnes, C. K., Østby, Y., Walhovd, K. B., Westlye, L. T., Due-Tønnessen, P., \& Fjell, A. M. (2010). Neuroanatomical correlates of executive functions in children and adolescents: A magnetic resonance imaging (MRI) study of cortical thickness. Neuropsychologia, 48(9), 2496-2508. https://doi.org/10.1016/j.neuropsychologia.2010.04.024

Tamnes, C. K., Walhovd, K. B., Dale, A. M., Østby, Y., Grydeland, H., Richardson, G., Westlye, L. T., Roddey, J. C., Hagler, D. J., Due-Tønnessen, P., Holland, D., \& Fjell, A. M. (2013). Brain development and aging: Overlapping and unique patterns of change. NeuroImage, 68, 63-74. https://doi.org/10.1016/j.neuroimage.2012.11.039 
Theodoraki, T. E., McGeown, S. P., Rhodes, S. M., \& MacPherson, S. E. (2020). Developmental changes in executive functions during adolescence: A study of inhibition, shifting, and working memory. British Journal of Developmental Psychology, 38(1), 74-89. https://doi.org/10.1111/bjdp.12307

Viechtbauer, W. (2010). Conducting meta-analyses in R with the meta for package. Journal of Statistical Software, 36(3), 1-48. https://doi.org/10.18637/jss.v036.i03

Whiteside, D. M., Kealey, T., Semla, M., Luu, H., Rice, L., Basso, M. R., \& Roper, B. (2016). Verbal fluency: Language or executive function measure? Applied Neuropsychology: Adult, 23(1), 29-34. https://doi.org/10.1080/23279095.2015.1004574

Wu, J., Ge, Y., Shi, Z., Duan, X., Wang, L., Sun, X., \& Zhang, K. (2010). Response inhibition in adolescent earthquake survivors with and without posttraumatic stress disorder: A combined behavioral and ERP study. Neuroscience Letters, 486(3), 117-121. https://doi.org/10.1016/j. neulet.2010.07.040

Yang, R., Xiang, Y.-T., Shuai, L., Qian, Y., Lai, K.Y., Ungvari, G.S., Chiu, H.F. and Wang, Y.-F. (2014), Executive function in children and adolescents with posttraumatic stress disorder 4 and 12 months after the Sichuan earthquake in China. Journal of Child Psychology Psychiatry, 55, 31-38. https://doi.org/10.1111/jcpp.12089

Yasik, A. E., Saigh, P. A., Oberfield, R. A., \& Halamandaris, P. V. (2007). Posttraumatic stress disorder: Memory and learning performance in children and adolescents. Biological Psychiatry, 61(3), 382-388. https://doi.org/10.1016/j.biopsych.2006.06.005

Zelazo, P. D., \& Carlson, S. M. (2012). Hot and cool executive function in childhood and adolescence: Development and plasticity. Child Development Perspectives, 6, 354-360. https:// doi.org/10.1111/j.1750-8606.2012.00246.x

Zhang, Z., Peng, P., Eickhoff, S. B., Lin, X., Zhang, D., \& Wang, Y. (2021). Neural substrates of the executive function construct, age-related changes, and task materials in adolescents and adults: ALE meta-analyses of $408 \mathrm{fMRI}$ studies. Developmental Science, 1-35. https://doi.org/10.1111/desc.13111 